\title{
Expansão da fronteira agrícola sobre o Cerrado: o mapeamento do uso da terra no município de Diamantino-MT.
}

\author{
Expansion of the agricultural frontier over the Cerrado: the mapping of land use in the \\ municipality of Diamantino-MT.
}

AVELINO $^{1}$, E. N.

ed.avelino@hotmail.com;

\begin{abstract}
Resumo
A expansão da fronteira agrícola no Centro-Oeste brasileiro deu-se por meio da transformação das áreas ocupadas pelo bioma Cerrado em terras de cultivos agrícolas ligados ao agronegócio. Este artigo tem o objetivo de elaborar o mapeamento do uso da terra, no contexto do município de Diamantino, estado de Mato Grosso. A pesquisa fundamentou-se nas concepções teóricas de Natureza (PORTO-GONÇALVES, 2006); Geografia Socioambiental (Mendonça, 2001); Sensoriamento Remoto (NOVO, 2008); e Sensoriamento Remoto da Vegetação (PONZONI, 2012), buscando aplicar a técnica de classificação supervisionada, método MAXVER sobre as cenas da imagem do satélite Landsat 8, sensor OLI, órbita 227 , ponto 70 , de $17 / 09 / 2016$. Os resultados mostraram que as lavouras com cultivo mecanizado ocupam $60,5 \%$ da área estudada enquanto o Cerrado florestal e savânico distribuem-se por $39,4 \%$. Os resultados podem contribuir para a gestão territorial.
\end{abstract}

\begin{abstract}
The expansion of the agricultural frontier in the Brazilian Midwest resulted from the transformation of the areas occupied by the Cerrado biome into farmland linked to agribusiness. This article aims to elaborate the mapping of land use, in the context of the municipality of Diamantino, Mato Grosso state. The research was based on the theoretical conceptions of Nature (PORTOGONÇALVES, 2006); Socio-environmental Geography (Mendonça, 2001); Remote Sensing (NOVO, 2008); and Remote Sensing of Vegetation (PONZONI, 2012), seeking to apply the supervised classification technique, MAXVER method on the image scenes of Landsat 8 satellite, OLI sensor, orbit 227, point 70, of 09/17/2016. The results showed that mechanized crops occupy $60.5 \%$ of the studied area, while the Cerrado forest and savannas are distributed by $39.4 \%$. The results can contribute to territorial management.
\end{abstract}

Keywords: Agricultural frontier; Cerrado; Land use. terra.

\section{INTRODUÇÃO}

A expansão da fronteira agrícola no Centro-Oeste brasileiro deu-se por meio da transformação das áreas ocupadas pelo bioma Cerrado em terras de cultivos agrícolas ligados ao agronegócio, uma vez que a menor densidade de árvore e tamanho da vegetação facilitam o desmatamento do Cerrado com o uso de tratores (ROSS, 2009). Segundo Porto-Gonçalves (2013), nos últimos anos a ação do agronegócio transformou as paisagens contínuas da biota natural em terrenos fragmentados e dispersos, espremidos pelo domínio das monoculturas mecanizadas.

O Cerrado consiste no segundo maior bioma do país em área, ocupando pouco mais de $2.000000 \mathrm{~km}^{2}$, essa área corresponde a cerca de $25 \%$ do território brasileiro. Ademais, estimativas indicam mais de 6.000 espécies de árvores e 800 espécies de aves, além de uma grande variedade 
de peixes e outras formas de vida (BRASIL, 2007). Por conta dessas características, o Cerrado é considerado um dos biomas mais rico do planeta (MACHADO et al, 2004).

Apesar da importância ecológico-paisagística, nos últimos anos, 70\% a 80\% dos terrenos ocupados pelas formações florestais do cerrado estão convertidas em pastagens plantadas e em plantações agrícolas de cultivos mecanizados (ROSS, 2009). Além disso, faz-se importante destacar que no período de 2009-2010, o Brasil perdeu $6.469 \mathrm{~km}^{2}$ do bioma Cerrado (BRASIL, 2011). Quanto ao Mato Grosso, o terceiro maior estado brasileiro em área, a taxa de desmatamento do Cerrado foi de $769 \mathrm{~km}^{2}$ (BRASIL, 2011).

Os dados sobre a supressão do bioma Cerrado demonstram que as falhas de fiscalização e a dificuldade de cumprir as leis ambientais contribuíram para que fossem implantadas no Cerrado práticas de produção econômicas danosas à natureza, uma vez que contribuiu para o desaparecimento de espécies de animais, plantas, árvores e outras formas de vida. Em função desse processo de descaracterização da natureza com perdas ambientais, no âmbito da Geografia ocorreu o amadurecimento científico do termo Geografia Socioambiental. De acordo com Mendonça (2001),

O termo "sócio" aparece, então, atrelado ao termo "ambiental" para enfatizar o necessário envolvimento da sociedade enquanto sujeito, elemento, parte fundamental dos processos relativos à problemática ambiental contemporânea. (MENDONÇA, 2001, p. 117).

A contribuição do pesquisador fez entender que, na sociedade contemporânea, as pessoas se tornaram o principal agente causador de transformações ambientais, uma vez que as relações sociais passaram a ser norteadas com base na lógica industrial. Assim sendo, a pressão sobre a natureza tornou-se mais intensa do que sua capacidade de regeneração natural, desencadeando perdas ambientais em diferentes níveis de escala, sendo que as perdas locais são as que mais interferem na vida das pessoas.

Nesse contexto, as pesquisas que envolvem o mapeamento de diversas feições da superfície terrestre - as pastagens, as lavouras agrícolas, a silvicultura, as florestas -, entre outros temas, evidenciam a importância dos estudos sobre uso da terra para a compreensão do espaço. No âmbito do mapeamento do uso da terra, o sensoriamento remoto se tornou um recurso tecnológico fundamental, pois possui um conjunto de técnicas que permitem identificar, espacializar, qualificar e quantificar diferentes alvos ambientais (PONZONI et al, 2012).

No sensoriamento remoto voltado para o estudo da vegetação existem diferentes tipos de técnicas, entre as quais as técnicas de classificação automática de imagem de satélite. No universo 
das diversas propostas, destaca-se a classificação supervisionada, com o método (algoritmo) Máxima Verossimilhança - Maxver. Este algoritmo considera que todas as cenas que formam uma imagem de satélite têm distribuições equivalentes e calcula a probabilidade de um determinado pixel pertencer a uma classe de uso específica, realizando, em seguida, agrupamentos que são convertidos em áreas ou classe de uso (CROSTA, 1999)

Diante do exposto, o presente estudo concentra a sua atenção no recorte espacial do município de Diamantino, estado de Mato Grosso. A área de estudo possui uma extensão territorial de $8.239,10 \mathrm{~km}^{2}$ (IBGE, 2010) e de acordo com o último Censo Demográfico, a população de Diamantino era composta por 20.341 habitantes (IBGE, 2010), os quais 15.895 pessoas vivem na área urbana e 4.446 habitam a área rural.

A escolha do município de Diamantino como área de estudo considerou a importância que a escala municipal exerce no contexto da gestão pública, bem como a escassez de informações ambientais que pudessem traduzir a sua realidade geográfica. Portanto, este artigo tem o objetivo de elaborar o mapeamento do uso da terra, no contexto da área de estudo (figura 1).

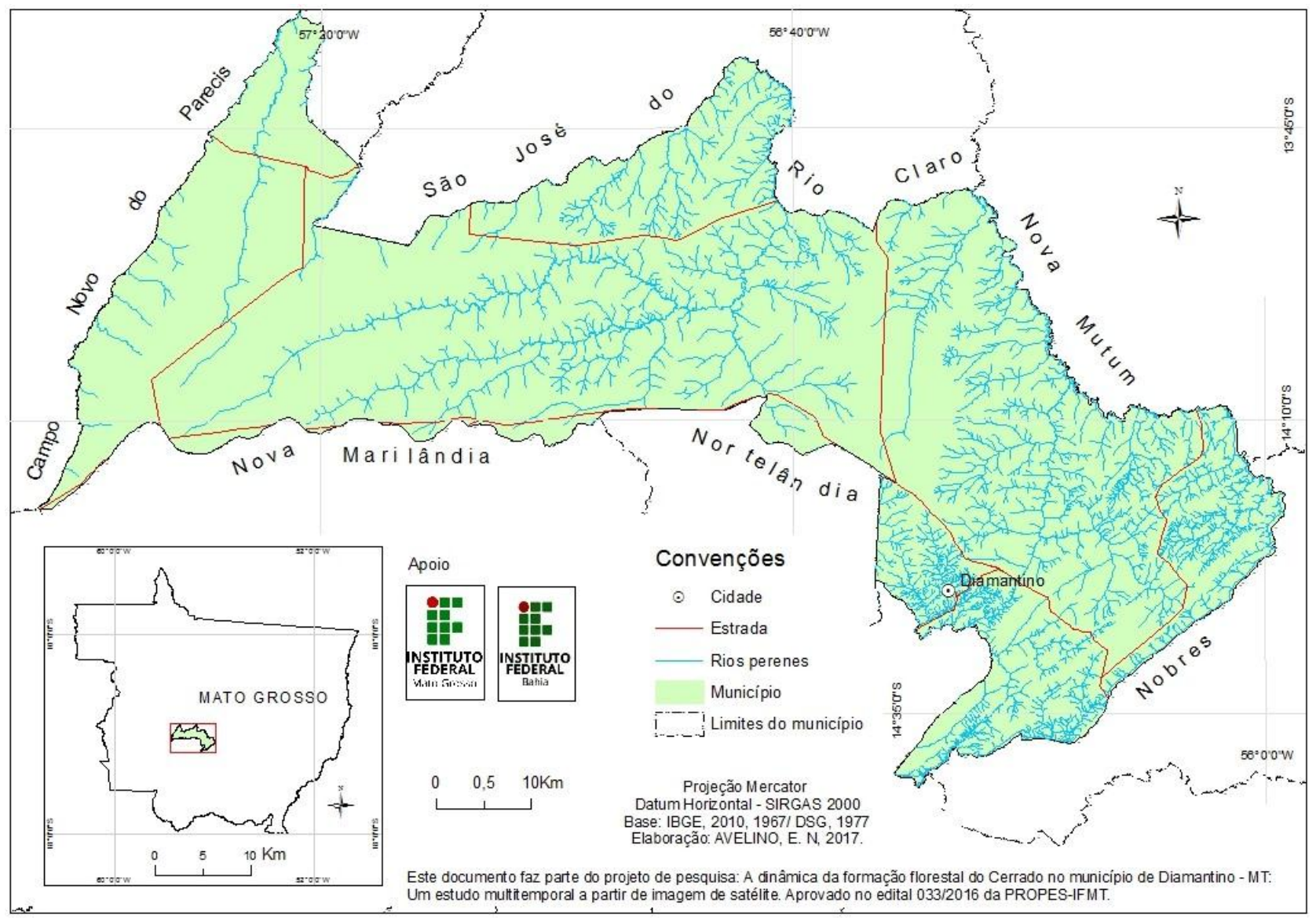

Figura 1: Localização da área de estudo, município de Diamantino-MT . Elaboração: Avelino, 2017. 


\section{METODOLOGIA}

O presente estudo fundamentou-se nas concepções teóricas de Geografia Socioambiental (MENDOÇA, 2001); Sensoriamento Remoto (CROSTA, 1999); e Sensoriamento Remoto da Vegetação (PONZONI, 2012). Ademais, utilizou a base cartográfica do Estado de Mato Grosso, com os limites territoriais do município de Diamantino, em formato vetorial, escala 1:100.000 cedida pelo IBGE (2010); a carta topográfica da área de estudo, em formato vetorial, escala de 1:100.000 disponibilizada pela Secretaria de Planejamento do Estado de Mato Grosso. Além disso, foram usadas as bandas 2, 3, 4, 5 e 6 do satélite Landsat 8, sensor OLI, resolução de 30 m, órbita 227, ponto 70, de 17/09/2016 adquiridas por meio do Instituto Nacional de Pesquisa Espaciais INPE, bem como os dados sobre a produção agrícola municipal (IBGE, 2016) de Diamantino, Mato Grosso .

Em seguida foi realizada a correção atmosférica das bandas 4 (vermelho) e 5 (infravermelho próximo) do satélite Landsat 8 por meio do método Dark Object Subtration - DOS, proposto por Chávez (1998). A aplicação do método DOS requer a conversão dos valores de números digitais (ND) das imagens para valores de parâmetros físicos como radiância e reflectância (PONZONI, 2012). Sendo assim, a transformação de ND em radiância bidirecional aparente considerou a equação (1) proposta por Markham \& Baker (1986 apud PONZONI, 2012).

$$
L_{0}(\lambda)=a_{i}+\frac{b_{i}-a_{i}}{255} \cdot D N
$$

Sendo que $a$ e $b$ constituem as radiâncias máximas e mínimas $\left(\mathrm{Wm}^{-2} \mathrm{sr}^{-1} \mathrm{~m}^{-1}\right)$ identificado pelo sensor OLI; os números digitais (ND) variam de 0 até 255 ; $i$ diz respeito às bandas $(4$ e 5 ) das imagens do Landsat 8. Na sequência, os valores de radiância bidirecional aparente são usados para se calcular a reflectância bidirecional aparente, por meio da seguinte equação (2).

$$
\rho_{i}=\frac{\pi \cdot L_{0}(\lambda) \cdot d^{2}}{\operatorname{Esun}(\lambda) \cdot \cos \theta}
$$

onde pi é a reflectância bidirecional aparente de cada banda; $\mathrm{L}_{0}(\lambda)$ consiste na radiância bidirecional aparente $\left(\mathrm{mW} \mathrm{cm}^{-2} \mathrm{sr}^{-1} \mu \mathrm{m}^{-1}\right), d$ se relaciona com a distância Sol-Terra em unidades astronômicas; $\operatorname{Esun}(\lambda)$ é a irradiância média do sol no topo da atmosfera $\left(\mathrm{mW} \mathrm{cm}^{-2} \mathrm{sr}^{-1} \mu \mathrm{m}^{-1}\right)$ e $\theta$ consiste no ângulo zenital solar.

Os procedimentos apresentados foram operacionalizados por meio da metodologia sistematizada em planilha Excel conforme proposta de Gurtler et al (2005). Sendo necessário 
também o uso de dados complementares tais como: histograma de frequência da banda 2 , o tipo de sensor, a data da imagem e o ângulo de elevação solar; estes constituem os metadados que acompanham as cenas do satélite Landsat 8.

Na sequência ocorreu a interpretação visual das imagens do satélite Landsat 8. Esta etapa englobou três fases distintas: a fotoleitura, a fotoanálise e a fotointerpretação. A fotoleitura consistiu na seleção de objetos ou feições de interesse nas cenas Landsat 8 OLI. Na fotoanálise houve a listagem dos objetos ou feições existentes na imagem de satélite. Na fotointerpretação, foi atribuído significado aos objetos ou feições a partir de associações feitas com base no raciocínio lógico e no dedutivo. Os produtos da fotoleitura, a fotoanálise e a fotointerpretação foram sistematizados sob a forma de chave de leitura e interpretação (figura 2).

\begin{tabular}{|c|c|c|}
\hline Classe de Corbetura Vegetal & Padrões Caracteristicos de Interpretação & Composição Colorida RGB \\
\hline $\begin{array}{l}\text { Área de cultivo de } \\
\text { gêneros agricolas }\end{array}$ & $\begin{array}{l}\text { Tonalidade/Cor: coloração com os tons de rosa e roxo; } \\
\text { Textura: terreno que apresenta pouca rugosidade; } \\
\text { Forma: forma geometrizada; retangular. }\end{array}$ & \\
\hline $\begin{array}{c}\text { Área de Floresta - } \\
\text { Fitofisiomia do Cerrado }\end{array}$ & $\begin{array}{l}\text { Tonalidade/Cor: verde } \\
\text { Textura: sem muita rugosidade; } \\
\text { Forma: formato não geometrizada; apresentando naturalidade }\end{array}$ & \\
\hline Área urbana & $\begin{array}{l}\text { Tonalidade/Cor: rosado escuro; } \\
\text { Textura: pouca rugosidade; } \\
\text { Forma: geometrizada em formato retangular; }\end{array}$ & \\
\hline Área de percurso do rio & $\begin{array}{l}\text { Tonalidade/Cor: azul escuro; } \\
\text { Textura: sem rugosidade; } \\
\text { Forma: distorcido. }\end{array}$ & \\
\hline Pivô de irrigação & $\begin{array}{l}\text { Tonalidade/Cor: verde claro; } \\
\text { Textura:baixa rugosidade; } \\
\text { Forma: geometrizada; circular. }\end{array}$ & \\
\hline Piscicultura & $\begin{array}{l}\text { Tonalidade/Cor: magenta } \\
\text { Textura: menor rugosidade; } \\
\text { Forma: retangular. }\end{array}$ & \\
\hline Solo exposto & $\begin{array}{l}\text { Tonalidade/Cor: branca; } \\
\text { Textura: sem rugosidade; } \\
\text { Forma: rentagular. }\end{array}$ & \\
\hline Vila Caeté & $\begin{array}{l}\text { Tonalidade/Cor: variçäo de branco e rosa; } \\
\text { Textura:baixa rugosidade; } \\
\text { Forma: presença de objetos retangulares. }\end{array}$ & 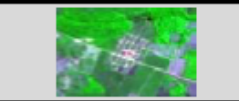 \\
\hline
\end{tabular}

Figura 2: Chave de leitura e interpretação, município de Diamantino-MT. Elaboração: Avelino, 2017.

A chave de leitura e interpretação auxiliou na elaboração da legenda do mapeamento do uso da terra da área de estudo, abrangendo as seguintes classes: cidade; agropecuária; Cerrado florestal e Cerrado savânico. Estas classes de uso formam o nível 1 de análise do mapeamento. Quanto à operacionalização da classificação supervisionada, por meio do método (algoritmo) Maxver sobre as cenas da imagem Landsat 8 OLI de 17/09/2016, correspondentes ao município de Diamantino, foram extraídas cinco amostras (escolha aleatória) de cada uma das classes de uso da terra definidas no nível 1 de análise do mapeamento. 
A definição do total de pontos amostrais necessários para serem visitados na etapa da atividade de campo, para assegurar a confiança do mapa de uso da terra, considerou a contribuição de Silva (2006), no que se refere ao procedimento usado (equação 6) para se mensurar o número adequado da amostragem de pontos e atestar a confiança de mapas temáticos. Por meio desse procedimento, foi encontrado um total de 50 pontos amostrais.

$$
n=\frac{Z^{2} \cdot p \cdot q}{E^{2}}
$$

onde:

$n=$ Tamanho da amostra de referência para cada classe temática;

$Z=$ ponto crítico para um limite de confiança de inclusão para o parâmetro exatidão real;

$p=$ exatidão desejada;

$q=1-\mathrm{p}$

$E=$ erro de amostragem admitido.

A distribuição da amostra sobre a área de estudo ocorreu com base no método da amostragem aleatória simples (Sampling Random). Esse método consiste na seleção de uma amostra de $n$ elementos de um total populacional de $\boldsymbol{N}$, de maneira que qualquer possível amostra tenha a mesma probabilidade de ser selecionada.

Por fim, foi aplicado nesse estudo O Prevalence and bias adjusted Kappa - coeficiente Kappa (IK) e o Prevalence and Bias Adjusted Kappa - Pabak. Estes são procedimentos estatísticomatemáticos usados para quantificar os erros de classificação temática existentes no mapa e, assim, mensurar o quanto o produto cartográfico corresponde à realidade. De acordo com Silva (2006), o coeficiente Kappa é calculado com base na seguinte equação (7):

Onde,

$$
I K=\frac{P_{o}-P_{e}}{1-P_{e}}
$$

$\mathrm{P} o=$ Proporção de simultaneidade observada.

$\mathrm{P} e=$ Proporção de simultaneidade esperada, com independência entre os observadores.

Os pesquisadores Landis e Koch (1977 apud SILVA, 2006) estabeleceram os seguintes intervalos para o coeficiente Kappa: 0,00 (sem correspondência); 0 - 0,20 (baixo); 0,21 - 0,40 (regular); 0,41 - 0,60 (moderado); 0,61 - 0,80 (substancial correspondência) e 0,81 - 1,00 (quase perfeito).

Quanto ao coeficiente Pabak (equação 8), ele é utilizado para ajustar o resultado do coeficiente Kappa, levando em consideração o desvio padrão e a prevalência das variáveis quantificadas. Dessa maneira, o Pabak torna mais apurado o resultado da classificação temática do mapa.

$$
\text { Pabak }=2 * P_{\mathrm{o}}-1
$$




\section{RESULTADOS E DISCUSSÃO}

A aplicação da técnica de classificação supervisionada, com base do método (algoritmo) Maxver sobre as cenas da imagem Landsat 8 OLI de 17/09/2016, referente à área de estudo, permitiu a elaboração da matriz de confusão, contendo os dados das classes de uso da terra, com erro total de 0,1 conforme tabela 1 .

Tabela 2: Matriz de confusão. Elaboração: Avelino, 2017.

\begin{tabular}{c|c|c|c|c|c|c}
\hline Classe de uso & Agropecuária & Cidade & Cerrado Floresta & Cerrado ss & Total & Erro de comissão \\
\hline Agropecuária & 16 & 0 & 0 & 2 & $\mathbf{1 8}$ & $(1-16 / 18)=0,12$ \\
\hline Cidade & 0 & 18 & 0 & 0 & $\mathbf{1 8}$ & $(1-18 / 18)=0$ \\
\hline Cerrado Floresta & 2 & 0 & 9 & 0 & $\mathbf{1 1}$ & $(1-9 / 11)=019$ \\
\hline Cerrado ss & 0 & 0 & 1 & 2 & $\mathbf{3}$ & $(1-2 / 3)=0,34$ \\
\hline Total & $\mathbf{1 8}$ & $\mathbf{1 8}$ & $\mathbf{1 0}$ & $\mathbf{4}$ & $\mathbf{5 0}$ & \\
\hline Erro de omissão & $(1-16 / 18)=0,12$ & $(1-18 / 18)=0$ & $(1-9 / 10)=0,1$ & $(1-2 / 4)=0,5$ & & 0,1 \\
\hline
\end{tabular}

O erro total foi obtido a partir do somatório dos pixels da diagonal principal (45) dividido pelo número de pixel (50) em seguida subtraiu-se o resultado encontrado de 1 . O dado do erro total consiste em um resultado expressivo, uma vez que o mapeamento com distorções grave corresponde a um valor igual ou próximo a 1.

$\mathrm{Na}$ sequência torna-se necessário destacar os dados do Índice Kappa a partir dos dados citados na matriz de confusão. Sendo assim, aplicação da equação do coeficiente Kappa pelos dados da matriz encontrou-se:

$$
\mathrm{K}=(\mathrm{D}-\mathrm{Q}) /(\mathrm{T}-\mathrm{Q})-\mathrm{K}=(45-15,4) /(50-15,4)-\mathrm{K}=29,6 / 34,6=0,85 \text {. }
$$

Sendo:

$\mathrm{D}=$ total de pixels com correlação entre os dados de campo e a interpretação correta;

$\mathrm{T}=$ número total de pixels examinados;

$\mathrm{Q}=$ Produto da relação entre total de linhas e colunas de cada classe, dividido pelo total de pontos;

Diante do exposto, constata-se que o resultado do coeficiente Kappa (IK) foi consistente porque segundo os valores de referência indicado por meio da escala de importância, sugerida por Landis e Koch (1977 apud Silva, 2003) para avaliar o Índice de Kappa, os valores entre 0,81 a 1,00 são considerados quase perfeitos.

Em seguida, foi calculado o Índice Pabak (Prevalence and bias adjusted Kappa) para tornar mais apurado o Índice Kappa. A correlação da equação do Pabak com os dados da matriz de confusão permitiu o seguinte resultado:

Pabak $(2.0,85-1)-$ Pabak $=1,7-1=0,70$. 
O mapa de uso da terra do município de Diamantino, estado de Mato Grosso, elaborado no presente estudo consta na figura 3.

A leitura e interpretação do mapeamento do uso da terra, no contexto do município de Diamantino, mostra que o agronegócio baseado no cultivo de grãos predomina na área de estudo (tabela 2).

Tabela 2: área ocupada pelas classes de uso da terra, município de Diamantino-MT. Elaboração:

Avelino, 2017.

\begin{tabular}{c|c|c|c}
\hline Classes de uso da terra & Área em $(\mathbf{k m})$ & Área em (ha) & Área em (\%) \\
\hline Agropecuária & $4.978,0735$ & $497.807,35$ & 60,50 \\
\hline Cerrado florestal & $2.226,3888$ & $222.638,88$ & 27,05 \\
\hline Cerrado savânico & $1.017,6382$ & $101.763,82$ & 12,36 \\
\hline Cidade & 7,1993 & 719,93 & 0,09 \\
\hline Total & $8.229,30$ & $822.929,98$ & 100 \\
\hline
\end{tabular}

A classe de uso da terra Agropecuária ocupa 60,50\% da área de estudo. Os principais gêneros cultivados são: o algodão (1.047, 622 hectares plantados); o milho (15.846, 517 hectares plantados); a soja (32.206, 387 hectares plantados); e o sorgo (740, 622 hectares plantados) segundo o IBGE (2016). O tamanho da área (497.807, 35 hectares) usada para a produção desses gêneros agrícolas (figura 4) evidencia a força que o agronegócio exerce sobre a área do município de Diamantino.

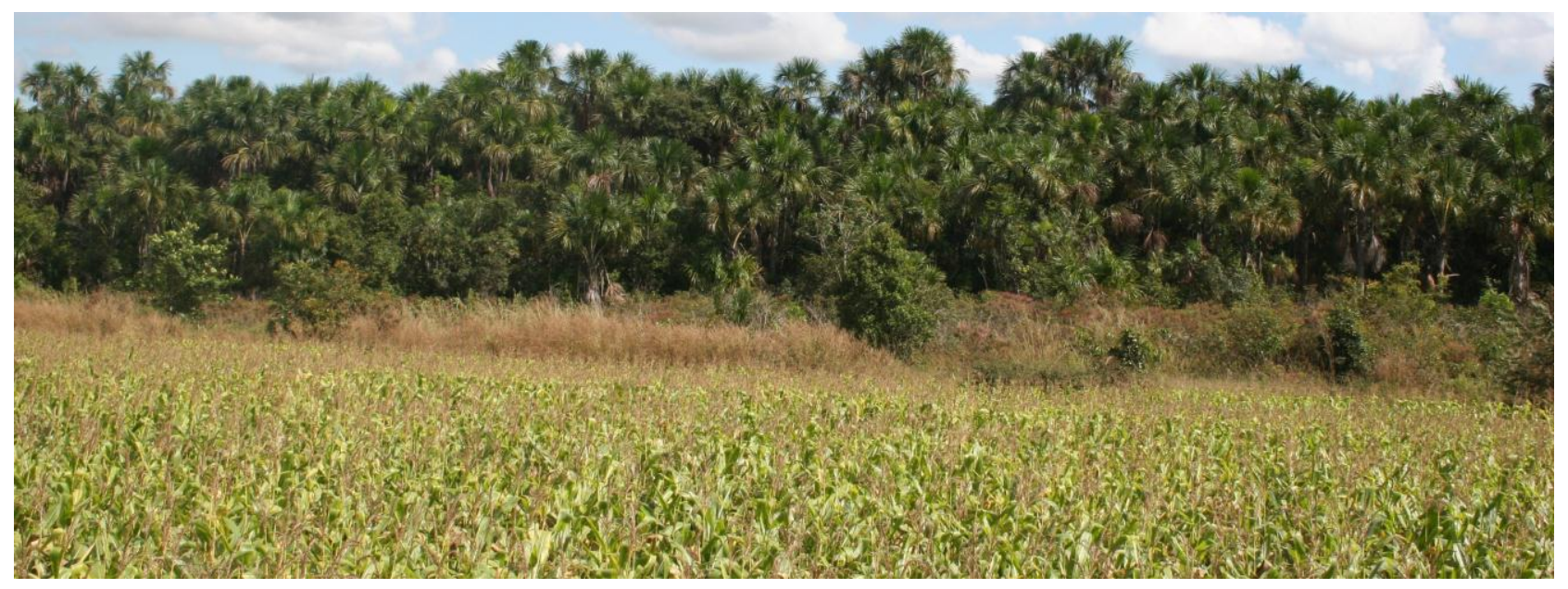

Figura 4: Avanço do cultivo de milho sobre área de Mata de Galeria, município de Diamantino-MT. Foto: Avelino, 2017. 


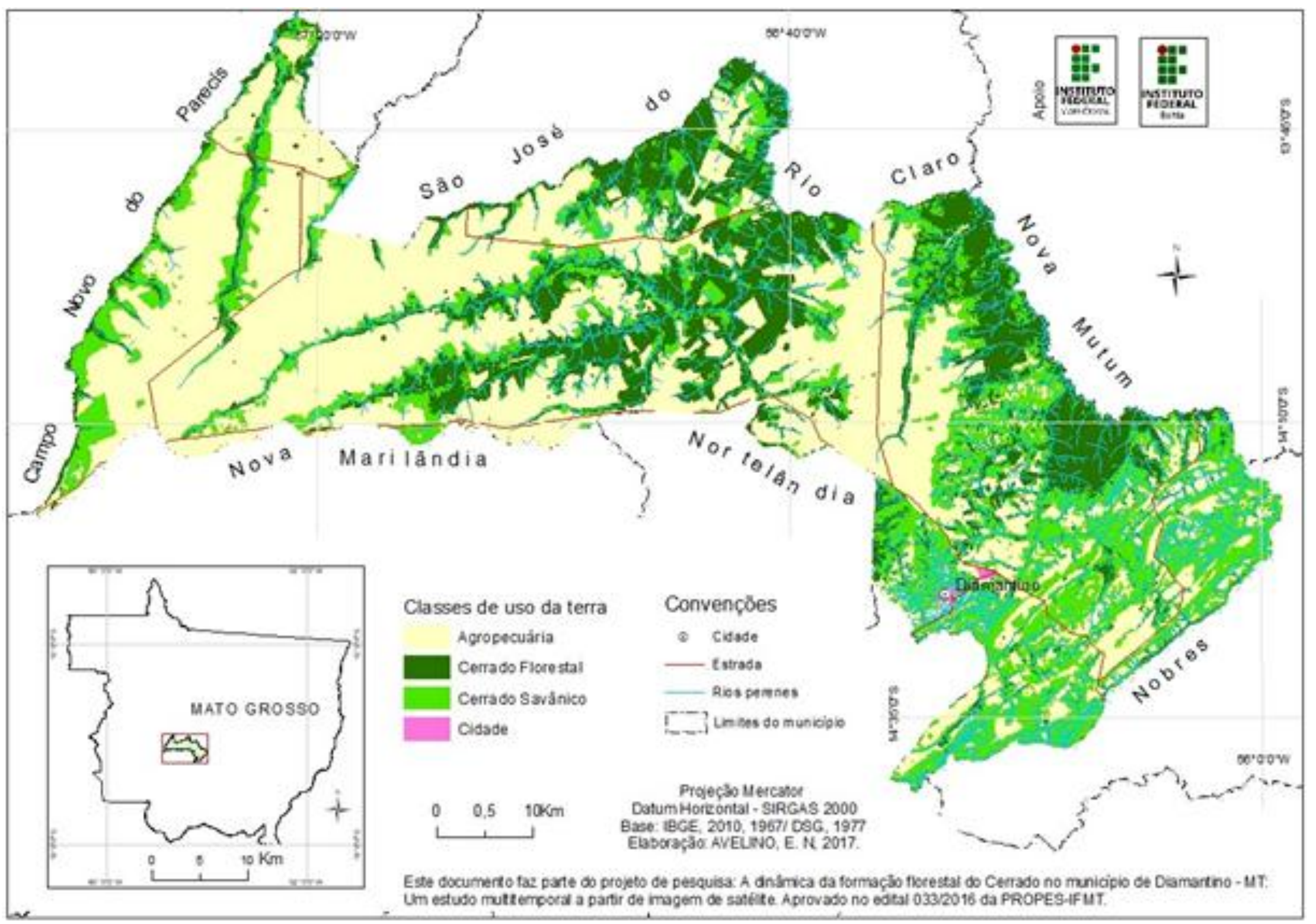

Figura 3: Mapa de uso da terra, município de Diamantino-MT. Elaboração: Avelino, 2017. 
A fitofisionomia do Cerrado em seu aspecto florestal ocupa cerca 27,05\% da área de estudo. O Cerrado florestal compreende as seguintes feições (WALTER; RIBEIRO, 1998): a Mata Ciliar, a Mata de Galeria, a Mata Seca e o Cerradão, estas fitofisionomias reunidas ocupam 222.638,88 hectares. As atividades de campo mostraram que apesar da existência de leis ambientais e instituições de fiscalização aconteceu a ainda acontece o avanço da agricultura comercial sobre as áreas onde se localizam os remanescentes do Cerrado florestal (figura 5).

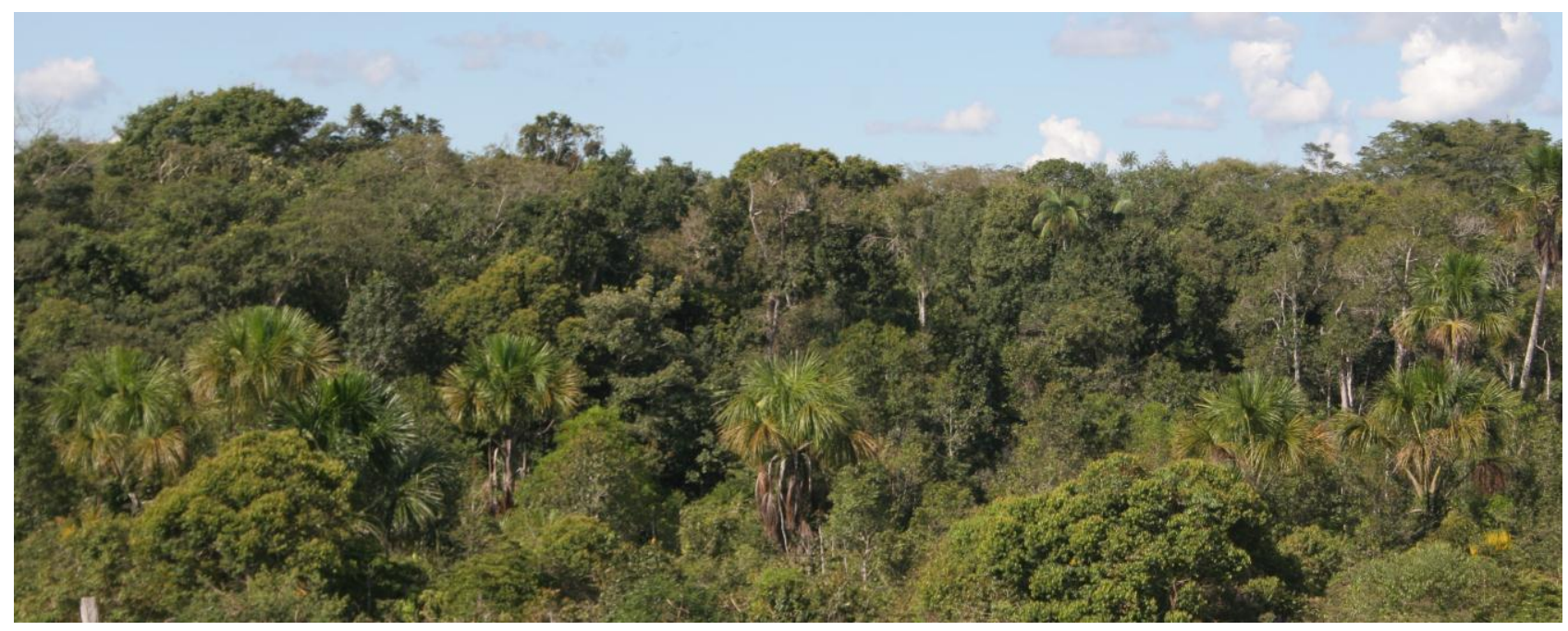

Figura 5: Feição do Cerrado florestal (Mata de Galeria com Buritis - Mauritia flexuosa), município de Diamantino-MT. Foto: Avelino, 2017.

A formação do Cerrado Savânica (figura 6) engloba a fitofisionomia do Cerrado Stricto Sensu, este se caracteriza pela fisionomia de estrato arbóreo e arbustivo-herbáceo definido, além disso, possuem árvores distribuídas aleatoriamente no terreno em diferentes densidades (WALTER; RIBEIRO, 1998). O Cerrado savânico distribui-se sobre 12,36\% da área de estudo, ocorrendo com maior frequência na parte Leste, devido à existência de falha geológica que reflete em terrenos ondulados, tornando essa área pouco atrativa para a agricultura comercial. Por sua vez, na parte central e Oeste do município de Diamantino, onde prevalecem terrenos planos, as áreas ocupadas pelo Cerrado savânico foram transformadas em espaço para a plantação de lavouras mecanziadas. 


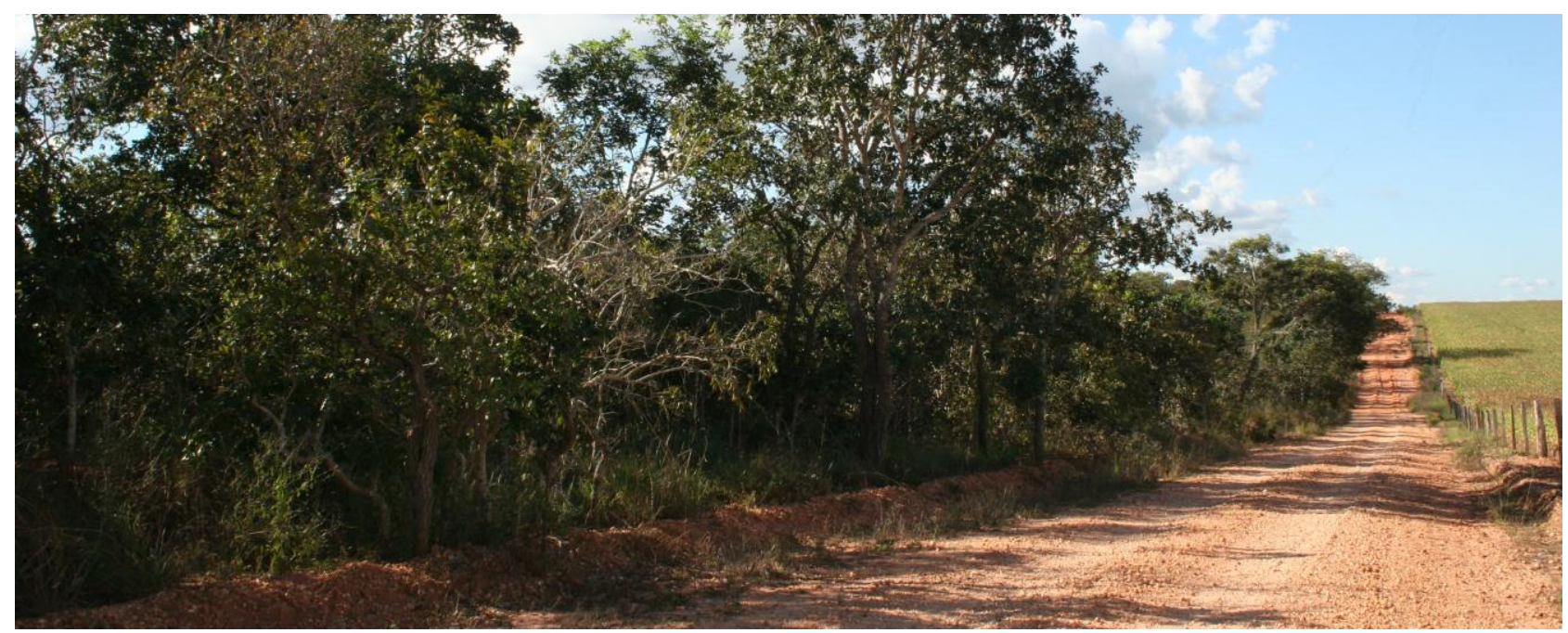

Figura 6: Fitofisionomia do Cerrado Savânico, cerrado stricto sensu, município de Diamantino-MT. Foto:

Avelino, 2017.

Por fim, a classe de uso da terra, cidade distribui-se sobre 719,93 hectares. No âmbito do presente estudo, a classe de uso cidade constitui a sede do município de Diamantino-MT, assim, consiste uma área composta por edificações e sistema viário, onde estão situados os poderes executivo, legislativo e judiciário. Nesse espaço, as superfícies artificiais, como é o caso de ruas asfaltadas, funciona como indicativo que ajuda a distinguir a cidade das áreas rurais (IBGE, 2010). Esta pesquisa reconheceu que existe limitação na aplicação das imagens de satélite Landsat 8 OLI para o estudo sobre recortes espaciais detalhados. No caso da área de estudo, a resolução espacial de 30 metros não deu subsídio para que fossem identificados os vetores de expansão da cidade de Diamantino. Apesar dessas limitações, o método de fotoanálise, fotoleitura e fotointerpretação aplicado sobre os dados extraídos da cena Landsat 8 OLI indicam a expansão da área correspondente à sede do município (figura 7).

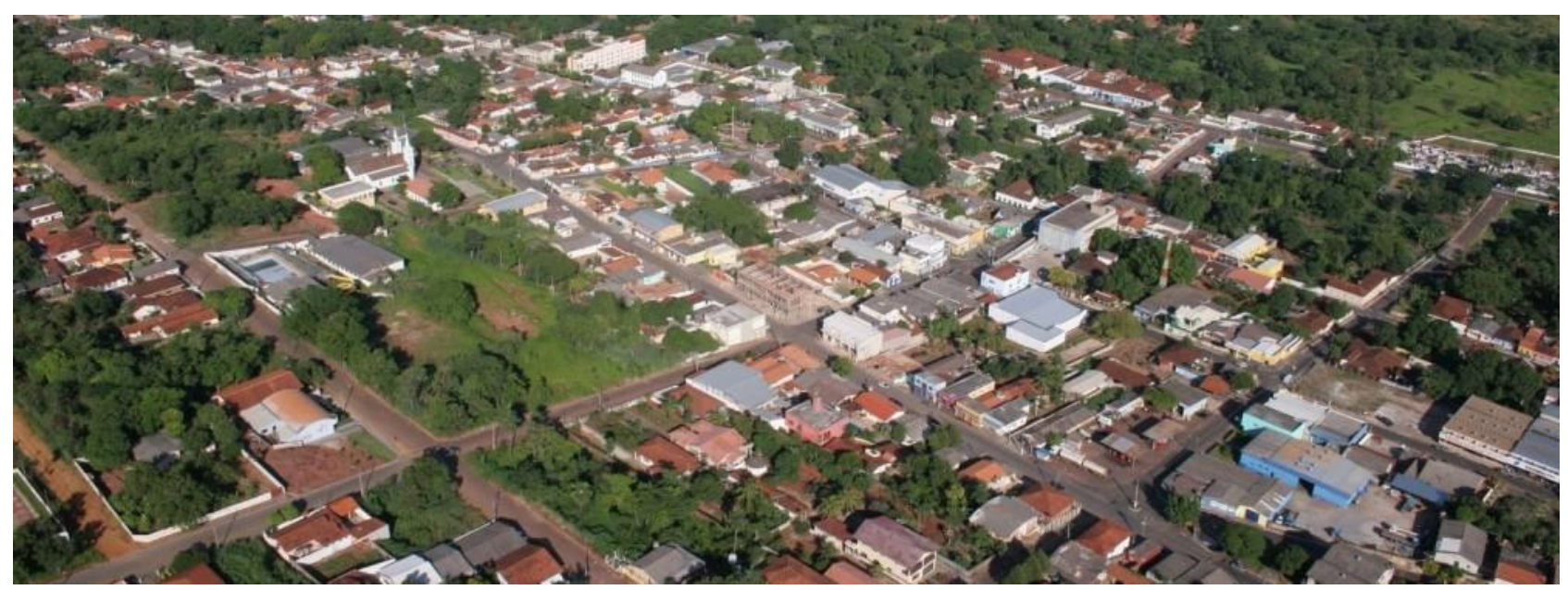

Figura 7: Centro da cidade de Diamantino, município de Diamantino-MT. Foto: Avelino, 2017. 


\section{CONSIDERAÇÕES FINAIS}

As concepções de Natureza (PORTO-GONÇALVES, 2006); Sensoriamento Remoto (NOVO, 2008); e Sensoriamento Remoto da Vegetação (PONZONI, 2012) ajudaram a compreender os pressupostos teóricos que existem na relação entre a cobertura vegetal e o sensoriamento remoto, permitindo a operacionalização dessa tecnologia no contexto da dilapidação do bioma Cerrado pelas atividades de produção econômica.

Por fim, os resultados do mapeamento do uso da terra, no município de Diamantino, estado de Mato Grosso, mostraram que 60\% da área estudada é ocupado com o cultivo de gêneros agrícolas ligados ao agronegócio. Quanto às fitofisionomias do bioma Cerrado no aspecto florestal e savânico, estas ocupam 39,41\% da área de estudo. Os resultados desse estudo podem subsidiar ações relacionadas à gestão do território.

\section{REFERÊNCIAS}

BRASIL. Ministério de Ciência e Tecnologia. Instituto Nacional de Pesquisas Espaciais. Monitoramento dos biomas brasileiro por satélite: monitoramento do Cerrado. São Paulo: Arcplan, 2011.

. MINISTÉRIO DO MEIO AMBIENTE. Biodiversidade do Cerrado e Pantanal: áreas e ações prioritárias para a conservação. Brasília: MMA, 2007.

CHÁVEZ, P. S. An improved dark-object subtraction technique for atmospheric scattering correction of multispectral data. Remote Sensing of Environment, 24, 459-479. 1998.

COUTINHO, L. M. O conceito de cerrado. Revista Brasileira de Botânica, v. 1, p. 17-23, 1978.

CROSTA, A. P. Processamento digital de imagem se sensoriamento remoto. Campinas: Universidade Estadual de Campinas, 1999.

GOODLAND, R. J. A.; FERRI, M. G. Ecologia do Cerrado. [S.1.]: Edusp/Itatiaia, 1979.

GURTLER, S.; EPIPHANIO, J.C.N.; LUIZ, A.J.B; FORMAGGIO, A.R. Planilha eletrônica para o cálculo da reflectância em imagens Tm e ETM+ Landsat. Revista Brasileira de Cartografia, No 57/02, 2005.

Huet, A.R.. A soil-adjusted vegetation index. Remote Sensing of Environment, Elsevier Science Publishing Co., New York, USA. 25:295-309. 1988.

IBGE. Censo Demográfico 2010. Rio de Janeiro: IBGE, 2010.

. Produção Agrícola Municipal 2016. Rio de Janeiro: IBGE, 2016. 
Justice, C. O.; Vermote, E.; Townshend, J.R.G.; Defries, R.; Roy, D.P.; Hall, D.K.; Salomonson, V.V.; Privette, J.L.; Riggs, G.; Strahler, A. The moderate resolution imaging spectroradiometer (MODIS): land remote sensing for global change research. IEEE Transactions on Geoscience and Remote Sensing, 36(4):1228-1249, 1998.

MACHADO, R. et al. Estimativas de perda da área do Cerrado brasileiro. http://www.ci.com (last accessed Janeiro 11, 2008): Conservation International, 2004.

MENDONÇA, F. Geografoa Socioambiental. Terra Livre, São Paulo, n 16, p 139-158, 2001.

NOVO, E. M. L. de Moraes. Sensoriamento Remoto: princípios e aplicações. 3ed. São Paulo: Blucher, 2008.

PONZONI, F. J.; Shimabukuro, Yosio Edemir. Sensoriamento Remoto no Estudo da Vegetação. São José dos Campos: Parêntese, 2012.

PORTO-GONÇALVES, C.V. A globalização da natureza e a natureza da globalização. Rio de Janeiro: Civilização Brasileira, 2013.

RIBEIRO, José Felipe; WALTER, Bruno Machado Teles. Fitofisionomias do Bioma Cerrado. In: Sano, S. M.; Almeida, S. P. (eds.). Cerrado: Ambiente e Flora. Planaltina: EMBRAPA CPAC, Cap. 3, p. 87-166, 1998.

ROSS, Jurandir Luciano Sanches. Ecogeografia do Brasil: subsídios para planejamento ambiental. São Paulo: Oficina de Texto, 2006, p. 23-61.

SILVA, Ardemírio de Barros. Análise quantitativa espacial de dados geológicos. In: CHAVES, Joselisa M.; ROCHA, WASHINGTON J. S. F. Geotecnologias: trilhando novos caminhos nas geociências. Salvador: SBG, 2006.

\section{AGRADECIMENTOS}

Este estudo faz parte do projeto de pesquisa intitulado A dinâmica da formação florestal do Cerrado no município de Diamantino-MT: Um estudo multitemporal a partir de imagem de satélite, aprovado no edital 033/2016, da Pró-Reitoria de Pesquisa e Inovação do IFMT. Ademais agradecemos ao IFBA campus Eunápolis por ajudar na viabilização do estudo.

Recebido em: 15/08/2018

Aceite para publicação em: 05/11/2018 